Portland State University

PDXScholar

\title{
Reproducing Published Results from In Silico Computer Models of the Acute Inflammatory Response to Severe Sepsis
}

\author{
Wayne W. Wakeland \\ Portland State University, wakeland@pdx.edu \\ Joe Fusion \\ Portland State University \\ Brahm Goldstein \\ Novo Nordisk, Inc.
}

Follow this and additional works at: https://pdxscholar.library.pdx.edu/sysc_fac

Part of the Biomedical Engineering and Bioengineering Commons, and the Chemicals and Drugs Commons

Let us know how access to this document benefits you.

\section{Citation Details}

Wakeland, W., Fusion, J., and Goldstein, B. (2006). Reproducing Published Results from In Silico Computer Models of the Acute Inflammatory Response to Severe Sepsis. Poster presentation at the International Conference on Complexity in Acute Illness (ICCAI), in Washington D.C.

This Poster is brought to you for free and open access. It has been accepted for inclusion in Systems Science Faculty Publications and Presentations by an authorized administrator of PDXScholar. Please contact us if we can make this document more accessible: pdxscholar@pdx.edu. 


\section{Reproducing Published Results from In Silico Computer Models of the Acute}

Portland State Inflammatory Response to Severe Sepsis

Wayne Wakeland ${ }^{1}$, Joe Fusion ${ }^{1}$, Brahm Goldstein ${ }^{2}$

${ }^{1}$ System Science Graduate Program, Portland State University, Portland, OR, USA

${ }^{2}$ Novo Nordisk, Inc., Princeton, NJ, USA

\section{Background}

Recent studies ${ }^{1,2}$ describe computer simulation models of the acute or systemic inflammatory response (AIR or SIR) to severe sepsis, a condition that can lead to multiple organ failure and death. One study used an agent-based model, while the other used differential equations (DEs) to simulate a randomized clinical trial. Both studies obtained results similar to the actual results from a successful clinical drug trial of severe sepsis ${ }^{3}$, suggesting that in silico (simulated) randomized clinical trials may be used to design more effective in vivo clinical trials.

\section{Objective}

- Reproduce published results of two in silico models of severe sepsis

- Study relationship between model complexity and experimental outcomes

\section{Methods}

(1) Used original investigator's agent-based model to re-run experiments; then ran same experiments with key model logic missing

(2) Implemented equations \& parameters in original paper; later, obtained equations and \#'s from the investigators and used them to run simulations

(3) Created very simple model; ran similar experiments

\section{Results}

(1) Agent-based model results successfully replicated. But nearly identical results were obtained with key portions of the model logic missing

(2) Unable to replicate the published DE model results due to numerous discrepancies in the equations and parameter values: simulated tissues always failed to recover

(3) Very simple model demonstrated outcomes ranging from full recovery to partial recovery (eradication of the initial infection, but oxygen deficit remains high) to failure to recover from the initial infection

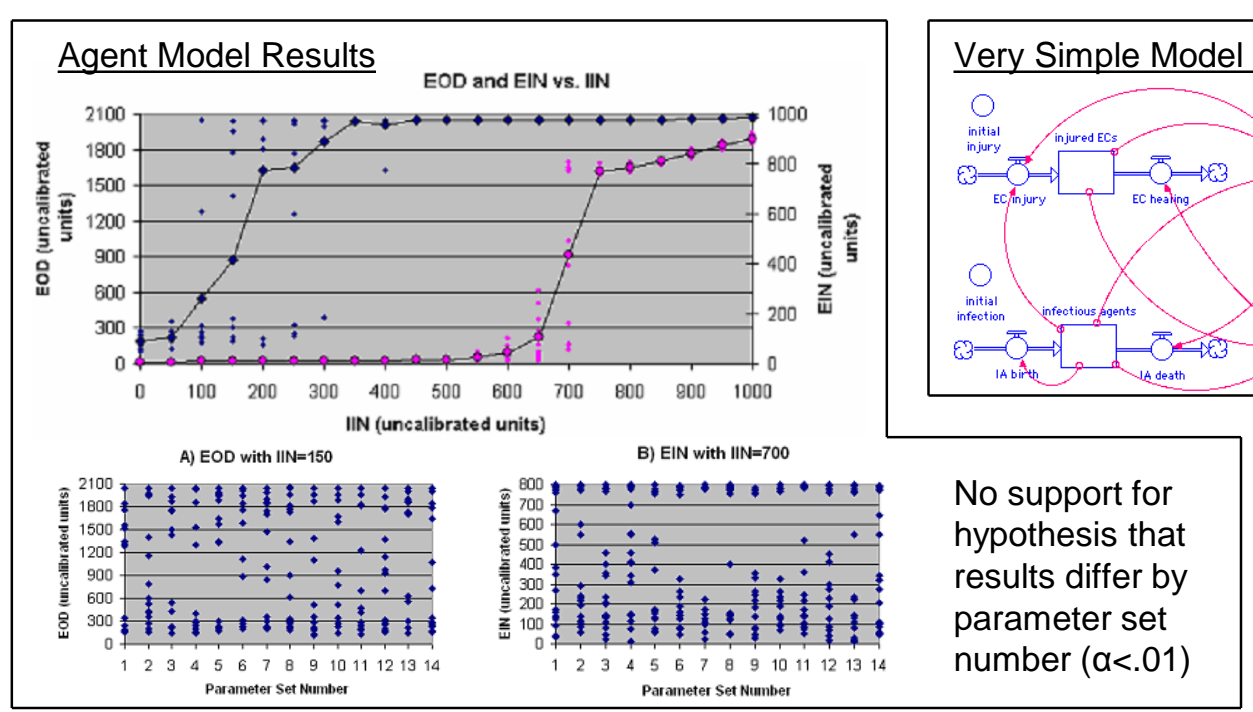

Discussion/Conclusion

- Replicating outcomes from model-based research is important

- Researchers must determine the simplest model that can generate the phenomenon of interest

- More research needed before in silico experiments can be used to improve clinical trial design. 